\title{
Eye Movement Profile: Quantification of Cognitive Workload
}

\section{Mondal K and Majumdar D*}

Defence Institute of Physiology and Allied Sciences, Defence Research and Development Organisation, India

*Corresponding author: Dr. Deepti Majumdar, Scientist- 'É', Ergonomics Laboratory, Defence Institute of Physiology and Allied Sciences, Defence Research and Development Organisation, Lucknow Road, Timarpur, Delhi-110054, India, Email: deepti_67@yahoo.com

\section{Mini Review}

Volume 4 Issue 4

Received Date: June 28, 2020

Published Date: August 10, 2020

DOI: $10.23880 /$ eoij-16000250

\section{Abstract}

Cognition itself is a qualitative variable but can be quantified in terms of different directly or indirectly associated factors. The eye movement profile is one of them that has been reported since the nineteenth century. Many researchers have considered eye movement as a window to access cognitive abilities in different areas if everyday activities. Moreover, a significant amount of original research and review articles have tried to establish various models to interpret work demand in terms of cognitive workload. However, those past articles are limited to very specific aspects of eye movement profile and with respect to specific tasks. The objective of the current review article was to formulate a model covering every possible aspect of eye movement research concerning human cognition specified with frequently considered eye movement events/profiles. The observation of the current review supports the past research that eye movement is strongly associated with cognition and eye movement profiles could be considered as potential markers for future cognitive psychology research. Significant evidence has been found for Pupilometry, Blink Profile, and Saccade Profile to prepare a model that can interpret cognitive workload. However, the lack of evidence was observed against the Fixation Profile strongly connected with cognition, which might be a relevant future scope in eye movement research. This review article singly would be helpful in the future to interpret cognitive workload through eye movement research across a diverse group of everyday activities.

Keywords: Eye Movement; Cognitive Workload; Pupil Diameter; Blink; Fixation; Saccad

\section{Introduction}

Cognition is a qualitative measure of the mental process could be quantified in terms of various determinants, which have a direct or indirect effect on cognition including quantitative and qualitative measures. To name a few, The Montreal Cognitive Assessment (MoCA) [1], Mini-Mental State Examination (MMSE) [2], standardized Mini-Mental State Examination (SMMSE) [3], Electroencephalogram (EEG) [4,5], neuropsychological vertigo inventory (NVI) [6] and vastly using Eye Movement Recording (EMR) since decades $[7,8]$ are globally considered as a method to quantify cognitive workload. The Eye Movement Recording is the interest of the current review article to discuss how different eye movement profile could be considered to quantify cognitive workload during performing different activities.

\section{Eye Movement and Types}

Eye movement is the orbital change in the position of the eye leading to change in the visual field to acquire visual signals. The eye can move voluntarily (to achieve a goal) or involuntarily (to response stimuli). Saccades, smooth pursuit, emergence, and vestibulo-ocular movements are the four basic types of eye movements $[9,10]$. In saccadic eye movements, the eye moves ballistically changing the point of fixation, which includes smaller movements during reading to larger movements during watching around a room $[9,11]$. Smooth pursuit eye movements correspond to the slow and voluntary movement of the eye to track the moving objects to keep on the fovea [9]. These two types of eye movement are conjugate eye movement that means both the eyes move in the same direction but in Vergence, eye movement is 
either convergence (near objects) or divergence (far objects) type when each of the eyes targeted the objects of different distances from the viewer $[9,12]$. Vestibulo-ocular eye movement is a compensatory eye movement that stabilizes the image on the fovea during head movement or locomotion. During head movement, vestibule-ocular eye movement occurs for the same distance but in the opposite direction of the head movement to make the focused objects stable in the fovea $[9,10]$.

\section{Eye Tracking}

Eye movements have significant qualitative and quantitative importance to predict human behavior and perception. Since the late 19 th century, scientists considered different techniques to measure eye movements, generally known as Eye Tracking. Visual observation techniques through mirror [13], required magnification lenses for larger eye movements [14] and microscope for small eye movements [15]. Later eye tracker adopted needed to be attached with the eye as a contact lens with a lever to record the movement of the eye on the recorder $[16,17]$. Lord and Wright adopted a photoelectric method to record eye movement based on the recording of corneal reflex [18]. Besides the photoelectric method, Yarbus considered another method used a mirror attached in a small rubber suction cup that was based on the recording of the reflected beam of light $[19,20]$. Another most popular method concerning the measurement of corneoretinal potential difference through electrooculography (EOG) to measure eye movement was first considered by Schott, Meyers, and Jacobson [21-24]. With the advancement of optical engineering, eye tracking has now become easy in terms of usability [25-28]. Significant amounts of researches have addressed the relation of eye movements and respective neuronal mechanisms [29-32].

\section{Eye Movement and Cognition}

Eye movements expedite a proficient sampling of visual information of interest. Sometimes, eye movement sampling was used to predict social behavior and emotions of a human being [33]. Many scientists have discussed that precise controlling mechanism of eye movements are the intensive future research scopes [34-37]. However, many researchers have considered eye movement as a potential tool to understand the different aspects of human behavior in the field of medical science, psychology, social sciences, human-computer interaction and computer science to name a few [38-46].

After the invention of the relationship between eye movements and speech perception/memory/language processing [47], many researcher have considered eye movement to investigate cognition and perceptual processing that has been discussed in the review of Huettig, et al. [48].
Rayner discussed that eye movement profile (fixation durations) was found to be influenced by cognitive processes $[7,49]$. Rayner also commented that the eye movement profile could able to provide significant information about human information processing $[7,49]$.

Underlying different cognitive processes, another review article claimed that eye movements reveal a significant amount of psychological progressions [50]. Their thought primarily based on two significantly explored eye movement research domains, visual search, and reading, to understand the mechanisms of key aspects of controlling eye movement. To understand the mechanism of eye movement control, the controlling mechanism and relationship between where and when to move the point of eye fixation are necessary to recognize the cognitive process replicated through eye movements. Further, the researcher concluded that where' and 'when' model of eye movement control are psychologically and physiologically separable $[51,52]$. Considering the above phenomenon, Simon and John concluded with a hope that future eye-movement research would reveal more cognitive controlling processes behind eye-movement patterns [50].

Henderson and his co-researcher recorded eye movements of twelve participants while performing four tasks: reading, pseudo-reading, scene search, and scene memorization to investigate whether the performed task could be accurately classified through the eye movements [39]. For that, they used multivariate pattern classification $[53,54]$ to train and tested on eye-movement measures to conclude that if it is possible to identify the tasks that participants engaged in their eye-movement pattern. The results suggested that eye movement provide significant information to classify engaged tasks further claiming that movements could be used to understand a person's cognitive state [39] corroborating with the top-down eye movement control theories for complex tasks [55-58]. Moreover, they have commented that besides the cognitive state, eye movements are also systematically influenced by the performed task [39]. Therefore, before designing a future study to understand human cognitive behavior one should precisely consider the tasks to be performed. However, a significant amount of study has considered evaluating human behaviors in everyday tasks like reading [39], visual searching [59], tea making [60], sandwich making [61], tapping a sequence of targets on a table [62], driving [63], table tennis [64], and cricket [65].

A recent study has considered eye movement recording along with several neuropsychological scores from ninety participants from three age groups (younger adults, older adults under 65 years and over 65 years of age) to understand the effect of age-related cognition on saccadic eye movements (SEMs). They have observed that SEMs are 
associated with and could be able to highlight the age-related decline of processing speed and attention in prosaccade and antisaccade tasks. They have also discussed that decrease in latency is related to processing speed decline and modification of executive attention plays a vital role in control and correct saccades, therefore, defining specific cognitive functions [66]. Another recent review article discussed that research of attention and eye movements are significantly explored [67-69] and pointed out that specific regions of the oculomotor system forms a spare network within the brain further expecting to process the information by many regions integrated with cortical connections and cooperating with the cognitive process [8]. In recent years, Konig, et al. commented that eye movement researches have reached a significant stage that could be integrated with other research methodologies to investigate the brain and mind [8]. Indeed, eye movement is significantly associated with cognitive loads and eye movement research is useful and could be considered as a measure to assess cognitive workload for single as well as combination of tasks $[70,71]$.

\section{Eye Movement Profile and Cognition}

Eye movement profiles represent every segment or events of eye movement which is broadly classified into four i.e., pupil diameter, blink, fixation, or visual intake and saccade. These are significantly considered and globally accepted measures in eye movement research. The following sections are highlighted with the purpose to discuss the different eye movement profiles and how they can be connected with the cognitive workload.

\section{Pupil Diameter / Pupilometry}

A significant amount of the theoretical accounts reveal that observed changes in pupil diameter are influenced by required cognitive effort [72] and pupil diameter plays a crucial role in analysing memory tasks [73]. Further, it is evident that the cognitive process demands a mental effort of attention and memory [74-77]. Progressive increasing task demands proportional increased mental effort further reflecting in changing pupil diameter. Indeed, the pupilometric profile is important to quantify the cognitive workload of a certain task. More specifically, pupil diameter has been found to be dilated as an influential effect of mental workload and vice versa [78-81]. However, ambient illumination has an influence on pupil diameter [82]. Therefore, before commencing pupil diameter as a potential marker for any future scientific research exposed to ambient illumination should critically considered.

\section{Blink Profile}

Researcher in the mid-20th century established that eye movement profile of blink rate could be a potential marker of attention to defining cognitive tasks $[83,84]$. A significant volume of evident reflected that decreased blink rate is associated with suppressed visual information [85], vocal difficulties to produce long sentences during a conversation [Cummins, 2011], more attention encountered tasks [83,84] and visually demanding tasks to minimize the chance of escaping insightful information [83,86-88]. Therefore, higher cognitive work demand manipulated with decreased blink rate $[89,90]$. In line with the findings of a decrease of blink duration as a function of increased workload [9193], most recent research of the current century observed that blink duration was found to decline as a function of increasing cognitive workload (Table 1) [78]. In case of more visual information to process central systems of the observer control to blink less [85]. Moreover, Meyer and Meyer, et al. addressed that the efferent nervous system controlling brain mechanisms is responsible for the muscular controlling of eyelids [94,95]. However, it is evident to produce a significantly higher frequency of blink for older children and adults than younger children [96,97]. John discussed that rate of blinking was found to increase as a function of time on the task [98]. Factors like eye injury, medication, and disease also have an influence on eye blink [99].

\section{Fixation Profile}

Three main overlapping or parallel events of Encoding of visual inputs, sampling of peripheral field and planning for next saccade takes place within a minimum fixation duration of 100 to $150 \mathrm{~ms}$ or within a typical fixation of 250 to $300 \mathrm{~ms}$ [100]. In modern techniques, instead of traditional detection of two separate fixations for even a single gaze, one larger and longer visual intake event has detected [101]. It is evident that fixations are strongly associated with the time to the evaluation of the task $[60,61]$. A limited number of fixations focused on irrelevant objects for a particular task, for example, fixation moves from the grasping and moving items to the next item to be moved $[60,61]$. Since the last century, the research focussing on the eye pauses (fixation) and the fundamental relationship with the cognitive process was the topmost priority [102,103]. Just and Carpenter proved that in sentence processing tasks, eye fixation and mental operations are systematically correlated, further establishing the proportional relationship between duration of gaze and duration of said tasks [104]. Moreover, a recent article discussed different aspects of fixations as a window to the cognitive process [8]. In this line, Barreas conclude that a higher cognitive workload can be associated with a significant increment of fixations count per second (Table 1) [70]. However, in spite of highlighted researches on the role of eye fixation study in cognitive psychology; there is a lack of significant evidence to identify a potential fixation model that could interpret cognitive work demand, being a specified scope of future research. Rather, eye fixation could 
be a potential marker to deliberate efficiency in reading, problem solving and information processing tasks (Table 1) [105]. Moreover, Loftus observed that fixation count could be the potential predictor of recognition memory for learning tasks [106]. Another group of researcher reported that the variation on fixations have a link with attention levels and working memory $[107,108]$. In particular, they claim that fixation duration enhances when an increment on the working memory. Interestingly, fewer fixations per word and more fixations per line were associated with the densely grouped, single-spaced document during performing reading tasks [109]. In line with similar observations towards difficult tasks, during artwork viewing, difficult processing was found to be associated with longer fixation duration (Table 1) [17]. On the other hand, longer fixations have produced for smaller and densely presented texts [109] and in the learning phase, later memory was appeared to be positively correlated with fixation duration [110]. Moreover, a wide range of fixation duration is responsible for the amount of information acquire with respect to different fixations [61]. Similarly, longer fixation duration was observed during observing face image then the natural scene which may be due to the critical analysis of the facial features (an individual's gender, age and familiarity, and their expressions) further revealing that different pattern of visuomotor activity is generated by face and natural scene [111]. Therefore, it is unclear whether fixation duration is directly associated with cognition and might be an important future research scope in the area of eye movement research.

\section{Saccade Profile}

A saccade is the ballistic movement of the eye corresponds to the amount of visual search on a scene. Generally, for understanding saccade is the distance between two fixations and the saccade count be quantity of fixation minus one. The close relation between attention and saccade is an established phenomenon [112-114]. Hoffman and Subramaniam and Shepherd, et al. (1986) claimed that before the occurrence of a saccadic movement participant first attend to that location [114,115]. Supporting the observations of Kowler [112], Hoffman and Subramaniam reported that to some extend oculomotor control of eye movement depend on attention [114].

Some studies from the current century suggested that there is a direct relationship between saccade count and cognitive workload. More specifically, the higher cognitive workload is associated with more number of saccades (Table 1) $[70,107,108,116]$. Therefore, the saccade profile not only could be a valid marker to measure cognitive workload but can also detect cognition in earlier states than eye fixations [70]. Average saccade velocities were also found to be enhanced with the enhancement of cognitive workload (Table 1) and reported to predict driver's perception of developing road accidents (Table 1) [71]. Smit and Gibergen suggested that at the early stage of saccades visual stimulus could speed up than initiate and guide the saccade. They also discussed that very short period of saccade latencies are probably due to the combination of sensory and motor time delay, not the time required for the computation of saccade properties [117]. However, the intrinsic value of visual information found to have a lesser but significant influence on the motor controls of saccades would keep in mind during designing of future research considering the saccade profile [118].

\begin{tabular}{|c|c|c|c|c|}
\hline \multirow[b]{2}{*}{ Parameters } & \multicolumn{2}{|c|}{$\begin{array}{c}\text { Interpretation in terms of cognitive work load/ } \\
\text { Performance }\end{array}$} & \multirow{2}{*}{$\begin{array}{l}\text { Influential } \\
\text { Factors }\end{array}$} & \multirow[b]{2}{*}{ References } \\
\hline & $\begin{array}{c}\text { Increase in } \\
\text { quantitative value of } \\
\text { the profile }\end{array}$ & $\begin{array}{l}\text { Decrease in quantitative value } \\
\text { of the profile }\end{array}$ & & \\
\hline Pupil Diameter & $\begin{array}{c}\text { Increase in pupil } \\
\text { diameter is associated } \\
\text { with higher cognitive } \\
\text { effort }\end{array}$ & $\begin{array}{c}\text { Decrease in pupil diameter is } \\
\text { associated with lower cognitive } \\
\text { effort }\end{array}$ & $\begin{array}{l}\text { Environmental } \\
\text { Illumination, } \\
\text { Chronologic } \\
\text { Age }\end{array}$ & $\begin{array}{l}\text { Cabestrero, et al. [80]; } \\
\text { Bruno, et al. [81]; Barry, et } \\
\text { al. [82]; Ulf and Ferne [78]; } \\
\text { Batmaz and Ozturk [79] }\end{array}$ \\
\hline $\begin{array}{l}\text { Blink Count/ } \\
\text { Frequency }\end{array}$ & $\begin{array}{l}\text { Lesser cognitive load } \\
\text { leads to increased } \\
\text { blink count/ frequency } \\
\end{array}$ & $\begin{array}{l}\text { Increases cognitive loads to } \\
\text { lesser blink count/ frequency }\end{array}$ & \multirow{2}{*}{$\begin{array}{c}\text { Age, Task } \\
\text { Duration, } \\
\text { Eye Injury, } \\
\text { Medication and } \\
\text { Disease }\end{array}$} & \multirow{2}{*}{$\begin{array}{c}\text { Volkmann, et al. [85]; } \\
\text { Fukuda, et al. [89]; Hayley } \\
\text { [90]; Van; Orden, et al. [91]; } \\
\text { Veltman and Gaillard [92]; } \\
\text { Zeghal, et al. [93]; Ulf and } \\
\text { Ferne [78]; Conrad [96]; } \\
\text { Lohr [97]; John [98]; Desai } \\
\text { [99] }\end{array}$} \\
\hline $\begin{array}{l}\text { Average Blink } \\
\text { Duration }\end{array}$ & $\begin{array}{l}\text { Less cognitive } \\
\text { workload produce } \\
\text { increased average } \\
\text { blink duration }\end{array}$ & $\begin{array}{c}\text { Higher cognitive workload } \\
\text { produce shorter average blink } \\
\text { duration }\end{array}$ & & \\
\hline
\end{tabular}




\begin{tabular}{|c|c|c|c|c|}
\hline $\begin{array}{l}\text { Fixation/Visual } \\
\text { Intake Count / } \\
\text { Frequency }\end{array}$ & $\begin{array}{c}\text { Increased fixation } \\
\text { count/ frequency is } \\
\text { associated with lesser } \\
\text { searching efficiency } \\
\text { and higher cognitive } \\
\text { workload } \\
\end{array}$ & $\begin{array}{l}\text { Decreased fixation count/ } \\
\text { frequency is associated with } \\
\text { higher searching efficiency and } \\
\text { lesser cognitive workload }\end{array}$ & & $\begin{array}{l}\text { Buswell [17]; Tichomirov } \\
\text { and Poznyanskaya, [102]; } \\
\text { Winikoff, [103]; Konig, } \\
\text { et al. [8]; Barreras [70]; }\end{array}$ \\
\hline $\begin{array}{c}\text { Average } \\
\text { Fixation/Visual } \\
\text { Intake Duration }\end{array}$ & $\begin{array}{l}\text { Increased average } \\
\text { fixation duration } \\
\text { reflects difficulty } \\
\text { in extracting } \\
\text { information/ more } \\
\text { task difficulty }\end{array}$ & $\begin{array}{l}\text { Shorter fixation duration } \\
\text { reflects easy to extracting } \\
\text { information/ less task difficulty }\end{array}$ & & $\begin{array}{c}\text { Rudmann, et al. [107]; } \\
\text { Chen, et al. [108]; Just } \\
\text { and Carpenter [104,105]; } \\
\text { Kolers, et al. [109] }\end{array}$ \\
\hline $\begin{array}{l}\text { Saccade Count/ } \\
\text { Frequency }\end{array}$ & $\begin{array}{c}\text { More difficulty } \\
\text { towards the selection } \\
\text { of a target/ higher } \\
\text { cognitive workload } \\
\text { leads to more number } \\
\text { of saccade count/ } \\
\text { frequency }\end{array}$ & $\begin{array}{c}\text { Less difficulty towards the } \\
\text { selection of a target/ less } \\
\text { cognitive workload leads to } \\
\text { less number of saccade count/ } \\
\text { frequency }\end{array}$ & \multirow{2}{*}{$\begin{array}{l}\text { Intrinsic } \\
\text { value of visual } \\
\text { information }\end{array}$} & \multirow{2}{*}{$\begin{array}{l}\text { Barrios, et al. [116]; Chen, } \\
\text { et al. [108]; Rudmann, et } \\
\text { al. [107]; Barreras [70]; } \\
\text { Biswas and Prabhakar [71]; } \\
\text { Smit and Gisbergen [117]; } \\
\text { Xu-Wilson, et al. [118] }\end{array}$} \\
\hline $\begin{array}{l}\text { Average Saccade } \\
\text { Velocity }\end{array}$ & $\begin{array}{l}\text { More task difficulty/ } \\
\text { enhanced cognitive } \\
\text { workload produce } \\
\text { high average saccade } \\
\text { velocity }\end{array}$ & $\begin{array}{l}\text { Less task difficulty/ reduced } \\
\text { cognitive workload produce less } \\
\text { average saccade velocity }\end{array}$ & & \\
\hline
\end{tabular}

Table 1: Eye movement profile as a function of cognitive workload/performance and others influential factors.

\section{Conclusion}

Observation of the current review article corroborates with the observation of Rayner [7,49], Simon and John [50], Huettig, et al. [48], Henderson, et al. [39], Konig, et al. [8], Barreras [70], and Biswas and Prabhakar [71] that the eye movement profiles have a significant correlation with the human cognition and the eye movement could be considered as a potential method to interpret the cognitive abilities of the participants engaged in the diverse group of daily activities. In particular, an eye movement model has been prepared (Table 1) on the basis of significantly proven eye movement profiles of Pupilometry, Blink, and Saccade which would be helpful in the future to interpret cognitive workload across a diverse group of everyday activities. However, future eye movement research scope could be effective on Fixation Profile finding the link with cognition has been inadequately reported.

\section{References}

1. Nasreddine ZS, Natalie AP, Valérie B, Simon C, Victor W, et al. (2005) The Montreal Cognitive Assessment, MoCA: a brief screening tool for mild cognitive impairment. Journal of the American Geriatrics Society 53(4): 695699.
2. Folstein MF, Folstein SE, McHugh PR (1975) Mini-mental status" A practical method for grading the cognitive state of patients for the clinician. Journal of Psychiatric Research 12(3): 189-198.

3. Molloy DW,Standish TI(1997) Aguide to the standardized Mini-Mental State Examination. Int Psychogeriatr 9(S1): 87-150.

4. Daniel PM, Jens-Uwe K, Reinhard B, Galina I (2008) Quantification of cognitive-induced brain activity: An efficient method for online applications. Computers in Biology and Medicine 38(11-12): 1194-1202.

5. Al-barrak L, Kanjo E, Younis EMG (2017) NeuroPlace: Categorizing urban places according to mental states. PLoS ONE 12(9): e0183890.

6. Liu APAYF, Locklear TD, Sharon JD, Lacroix E, Nguyen SA, et al. (2019) Quantification of Cognitive Dysfunction in Dizzy Patients Using the Neuropsychological Vertigo Inventory, Otology \& Neurotology 40(7): e723-e731.

7. Rayner K (1978) Eye movements in reading and information processing. Psychological Bulletin 85(3): 618-660.

8. Konig P, Wilming N, Kietzmann TC, Ossandon JP, Onat S, 
et al. (2016) Eye movements as a window to cognitive processes. Journal of Eye Movement Research 9(5): 1-16.

9. Purves D, Augustine GJ, Fitzpatrick D (2001) Types of Eye Movements and Their Functions. Neuroscience, $2^{\text {nd }}$ (Edn.), Sinauer Associates, Sunderland (MA).

10. Sereno AB, Babin SL, Hood AJ, Jeter CB (2009) Executive Functions: Eye Movements and Neuropsychiatric Disorders. Encyclopedia of Neuroscience, pp: 117-122.

11. Krauzlis RJ (2005) The control of voluntary eye movements: new perspectives. The Neuroscientist 11(2): 124-137.

12. Charles PD, Milea D, Muri RM (2004) Eye movement control by the cerebral cortex. Current Opinion in Neurology 17(1): 17-25.

13. Javal EL (1879) Essay on reading. Ann Oculist Physiology 82: 242-253.

14. Newhall SN (1928) Instrument for observing ocular movements. Amer J Psychol 40: 628.

15. Gassovskii LN, Nikolskaya NA (1941) Mobility of the eye during fixation. Problemy Fiziol Optiki 1:173.

16. Huey EB (1908) The psychology and pedagogy of reading: With a review of the history of reading and writing and of methods, text, and hygiene of reading, MacMillan Company, New York.

17. Buswell GT (1935) How people look at pictures, University of Chicago Press, USA.

18. Lord MP, Wright WD (1948) Eye movements during monocular fixation. Nature 162(4105): 25-26.

19. Yarbus AL (1954) Investigation of the principles governing eye movement in the process of vision. Doklady Akad Nauk SSSR 96(4): 732.

20. Yarbus AL (1967) Eye movements and vision, New York.

21. Scott E (1922) Deur Arch Klin Med 140:79.

22. Meyers I L (1929) Arch Neurol Psychiat 21:901.

23. Jacobson E (1930a) Amer J Physiol 91:575.

24. Jacobson E (1930b) Amer J Physiol 95:694

25. Carl C, Konig P, Engel AK, Hipp JF (2012) The saccadic spike artifact in MEG. NeuroImage 59(2): 1657-1667.

26. Bulea TC, Kilicarslan A, Ozdemir R, Paloski WH, Contreras-Vidal JL (2013) Simultaneous scalp electroencephalography (EEG), electromyography (EMG), and whole-body segmental inertial recording for multi-modal neural decoding. Journal of Visualized Experiments 77: 1-13.

27. Reis PMR, Hebenstreit F, Gabsteiger F, Tscharner von V, Lochmann M (2014) Methodological aspects of EEG and body dynamics measurements during motion. Frontiers in Human Neuroscience 8: 156.

28. Muller JA, Wendt D, Kollmeier B, Brand T (2016) Comparing Eye Tracking with Electrooculography for Measuring Individual Sentence Comprehension Duration. PLoS ONE 11(10): e0164627.

29. Trommershauser J, Glimcher PW, Gegenfurtner KR (2009) Visual processing, learning and feedback in the primate eye movement system. Trends in Neurosciences 32(11): 583-590.

30. Kowler E (2011) Eye movements: the past 25 years. Vision Research 51(13): 1457-1483.

31. Rucci M, Poletti M (2015) Control and functions of fixational eye movements. Annual Review of Vision Science 1(1): 499-518.

32. Gegenfurtner KR (2016) The Interaction Between Vision and Eye Movements. Perception 45(2): 1333-1357.

33. Emery NJ (2000) The eyes have it: the neuroethology, function and evolution of social gaze. Neurosci Biobehav Rev 24(6): 581-604.

34. Wolfe JM (1994) Guided search 2.0 a revised model of visual search. Psychon Bull Rev 1: 202-238.

35. Martinez-Conde S, Macknik SL, Hubel DH (2004) The role of fixational eye movements in visual perception. Nat Rev Neurosci 5(3): 229-240.

36. Foulsham T, Walker E, Kingstone A (2011) The where, what and when of gaze allocation in the lab and the natural environment. Vision Research 51(17): 19201931.

37. Rucci M, Victor JD (2015) The unsteady eye: an information-processing stage, not a bug. Trends Neurosci 38(4): 195-206.

38. Raudonis V, Simutis R, Narvydas G (2009) Discrete eye tracking for medical applications. In: 2009 $2^{\text {nd }}$ International Symposium on Applied Sciences in Biomedical and Communication Technologies, Bratislava, pp: 1-6.

39. Henderson JM, Shinkareva SV, Wang J, Luke SG, Olejarczyk 
J (2013) Predicting cognitive state from eye movements. PLoS ONE 8(5): e64937.

40. Wu SL, De Liao L, Lu SW, Jiang WL, Chen SA, et al. (2013) Controlling a human-computer interface system with a novel classification method that uses electrooculography signals. Biomed Eng IEEE Trans 60(8): 2133-2141.

41. Bulling A, Ward J, Gellersen H, Tröster G (2011) Eye movement analysis for activity recognition using electrooculography. Pattern Anal Mach Intell IEEE Trans 33(4): 741-753.

42. Bulling A, Zander TO (2014) Cognition-aware computing. IEEE Perv Comput 13: 80-83.

43. Bixler R, D'Mello SK (2015) Automatic gaze-based user-independent detection of mind wandering during computerized reading. User Model User Adapt Inter 26: 33-68.

44. Steil J, Bulling A (2015) Discovery of everyday human activities from long-term visual behaviour using topic models. In: Proceedings of the 2015 ACM International Joint Conference on Pervasive and Ubiquitous Computing (UbiComp 2015) (Osaka), pp: 75-85.

45. Katarzyna H, Pawel K (2018) Application of eye tracking in medicine: A survey, research issues and challenges. Computerized Medical Imaging and Graphics 65: 176190.

46. Brunye TT, Drew T, Weaver DL, Elmore JG (2019) A review of eye tracking for understanding and improving diagnostic interpretation. Cognitive Research 4: 7.

47. Cooper RM (1974) The control of eye fixation by the meaning of spoken language: A new methodology for the real-time investigation of speech perception, memory, and language processing. Cognitive Psychology 6(1): 84107.

48. Huettig F, Rommers J, Meyer AS (2011) Using the visual world paradigm to study language processing: A review and critical evaluation. Acta Psychol (Amst) 137(2): 15171.

49. Rayner K (1977) Visual attention in reading: Eye movements reflect cognitive processes. Memory \& Cognition 5(4): 443-448.

50. Simon PL, John MF (2000) Saccadic eye movements and cognition. Trends in Cognitive Sciences 4(1): 6-14.

51. Rayner K, McConkie GW (1976) What guides a reader's eye movements? Vision Research 16(8): 829-837.
52. Rayner K, Pollatsek A (1981) Eye movement control during reading: evidence for direct control. Q J Exp Psychol 33(4): 351-373.

53. Mitchell TM (1997) Machine learning. New York, NY: McGraw Hill.

54. Bishop CM (2006) Pattern recognition and machine learning. New York, NY: Springer.

55. Reichle ED, Pollatsek A, Fisher DL, Rayner K (1998) Toward a model of eye movement control in reading. Psychol Rev 105(1): 125-157.

56. Torralba A, Oliva A, Castelhano MS, Henderson JM (2006) Contextual guidance of eye movements and attention in real-world scenes: The role of global features in object search. Psychol Rev 113(4): 766-786.

57. Engbert R, Longtin A, Kliegl R (2002) A dynamical model of saccade generation in reading based on spatially distributed lexical processing. Vision Res 42(5): 621636.

58. Nuthmann A, Henderson JM (2012) Using CRISP to model global characteristics of fixation durations in scene viewing and reading with a common mechanism. Visual Cognition 20(4-5): 457-494.

59. Bhattacharyya D, Chowdhury B, Chatterjee T, Pal M, Majumdar D (2014) Selection of character/background colour combinations for onscreen searching tasks: An eye movement, subjective and performance approach. Displays 35(3): 101-109.

60. Land MF, Mennie N, Rusted J (1999) Eye movements and the roles of vision in activities of daily living: Making a cup of tea. Perception 28(11): 1311-1328.

61. Hayhoe M, Shrivastrava A, Myruczek R, Pelz J (2003) Visual memory and motor planning in a natural task. Journal of Vision 3(1): 49-63.

62. Epelboim J, Steinman R, Kowler E, Edwards M, Pizlo Z, et al. (1995) The function of visual search and memory in sequential looking tasks. Vision Reseurch 35(23-24): 3401-3422.

63. Land MF, Lee DN (1994) Where we look when we steer. Nature 369: 742-744.

64. Land MF, Furneaux S (1997) The knowledge base of the oculomotor system. Philosophical Transactions of the Royal Society of London 352(1358): 1231-1239.

65. Land MF, McLeod P (2000) From eye movements to actions: How batsmen hit the ball. Nature Neuroscience 


\section{3: $1340-1345$.}

66. Nicolas N, Blanche V, Marine D, Pierre V, Éric L (2017) Saccadic eye movements: what do they tell us about aging cognition? Aging Neuropsychology and Cognition 24(5): 575-599.

67. Groner R, Groner MT (1989) Attention and EyeMovement Control - an Overview. European Archives of Psychiatry and Clinical Neuroscience 239(1): 9-16.

68. Pashler HE, Sutherland S (1998) The psychology of attention, MIT press.

69. Pashler H (2016) Attention, Psychology Press.

70. Barreras A (2017) Measuring Cognitive Load using EyeTracking in visual search tasks. Thesis for the Degree Master of Science. University of Konstanz.

71. Biswas P, Prabhakar G (2018) Detecting drivers' cognitive load from saccadic intrusion. Transportation Research Part F 54: 63-78.

72. Cabestrero R, Crespo A, Quirós P (2009) Pupillary dilation as an index of task demands. Perceptual and Motor Skills 109(3): 664-678.

73. Karatekin C, Marcus DJ, Couperus JW (2007) Regulation of cognitive resources during sustained attention and working memory in 10-year-olds and adults. Psychophysiology 44(1): 128-144.

74. Kahneman D (1973) Attention and effort. Englewood Cliffs, NJ: Prentice-Hall, pp:1-178.

75. Cowan N (1995) Attention and memory: an integrated framework. New York: Oxford Univer, Press.

76. Cowan N (2001) The magical number 4 in short-term memory: a reconsideration of mental storage capacity. Behavioral and Brain Sciences 24(1): 87-185.

77. Cowan N (2008) What are the differences between longterm, short-term, and working memory? In: Sossin WS, Lacaille JC, Castellucci VF, Belleville S (Eds.), Essence of memory. (Progress in Brain Research, Amsterdam: Elsevier 169: 323-338.

78. Ulf A, Ferne JF (2006) Using eye movement activity as a correlate of cognitive workload. International Journal of Industrial Ergonomics 36(7): 623-636.

79. Batmaz I, Ozturk M (2008) Using Pupil Diameter Changes for Measuring Mental Workload under Mental Processing. Journal of Applied Sciences 8: 68-76.

80. Cabestrero R, Crespo A, Quiros P (2009) Pupillary dilation as an index of task demands. Perceptual and Motor Skills 109(3): 664-678.

81. Bruno L, Sylvain S, Gustaf G (2012) Pupillometry a window to the preconscious? Per-spectives on psychological science 7(1): 18-27.

82. Barry W, David W, David BE, Nicholas JP (1994) Factors Affecting Light-Adapted Pupil Size in Normal Human Subjects. Investigative Ophthalmology \& Visual Science 35(3): 1132-1137.

83. Drew GC (1951) Variations in reflex blink-rate during visual-motor tasks. Quarterly Journal of Experimental Psychology 3(2): 73-88.

84. Poulton EC, Gregory RL (1952) Blinking during Visual Tracking. Quarterly Journal of Experimental Psychology $4(2): 57-65$.

85. Volkmann FC, Riggs LA, Moore RK (1980) Eyeblinks and visual suppression. Science 207(4433): 900-902.

86. Baumstimler Y, Parrot J (1971) Stimulus generalization and spontaneous blinking in man involved in a voluntary activity. Journal of Experimental Psychology 88(1): 95102.

87. Kennard DW, Glaser GH (1964) An analysis of eyelid movements. Journal of Nervous and Mental Disease 139(1): 31-48.

88. Stern JA, Walrath LC, Goldstein R (1984) The endogenous eye blink. Psychophysiology 21(1): 22-33.

89. Fukuda K, Stern JA, Brown TB, Russo MB (2005) Cognition, blinks, eye-movements, and pupillary movements during performance of a running memory task. Aviation Space Environmental Medicine 76(7): C75-C85.

90. Hayley L (2013) The effect cognitive load has on eye blinking. The Plymouth Student Scientist 6(1): 206-223.

91. Van Orden KF, Jung TP, Makeig S (2000) Combined eye activity measures accurately estimate changes in sustained visual task performance. Biological Psychology 52(3): 221-240.

92. Veltman JA, Gaillard AWK (1998) Physiological workload reactions to increasing levels of task difficulty. Ergonomics 41(5): 656-669.

93. Zeghal K, Grimaud I, Hoffman E, Rognin L (2002) Delegation of spacing tasks from controllers to flight crew. Impact of controller monitoring tasks. In: Proceedings of the IEEE/AIAA Digital Avionics Systems 
Conference, 2B3. IEEE Press, Irvine, CA, pp: 1-9.

94. Meyer DR (1953) On the interaction of simultaneous response. Psychological Bulletin 50(3): 204-220.

95. Meyer DR, Bahrick HP, Fitts PM (1953) lncentive, anxiety, and the human blink rate. Journal of Experimental Psychology 45(3): 183-187.

96. Conrad A (1955) Development of blinking during the first year. Unpublished doctoral dissertation, Free University of Berlin, Germany.

97. Lohr W (1960) Behavior and eye blinks in 10-18-weekold infants performing perceptual tasks. Zeitschrift far experimentelle und angewandte Psychologie 4: 493-531.

98. John AS, Donna B, David S (1994) Blink Rate: A Possible Measure of Fatigue 36(2): 285-97.

99. Desai YS (2012) Driver's alertness detection for based on eye blink duration via EOG \& EEG. International Journal of Advanced Computer Research 2(4): 93-99.

100. Viviani P (1990) Eye Movements and Their Role in Visual and Cognitive Processes, Chapter 8, Elsevier Science, Amsterdam.

101. SMI (2016) BeGaze Manual, Version 3.7, SensoMotoric Instruments, pp: 333-334.

102. Tichomirov GK, Poznyanskaya ED (1966) An investigation of visual search as a means of analyzing heuristics. Voprosy Psikhologii 5(2): 3-15.

103. Winikoff A (1967) Eye movements as an aid to protocol analysis of problem solving behavior. Unpublished doctoral dissertation, Carnegie-Mellon University, Pittsburgh, PA.

104. Just MA, Carpenter PA (1976a) Eye Fixations and Cognitive Processes. Cognitive Psychology 8: 441-480.

105. Just MA, Carpenter PA (1976b) The role of eyefixation research in cognitive psychology. Behavior Research Methods \&Instrumentation 8(2): 139-143.

106. Loftus GR (1972) Eye fixations and recognition memory for pictures. Cognitive Psychology 3(4): 525551.

107. Rudmann D, McConkie G, Zheng X (2003) Eye tracking in Cognitive State Detection for HCI. ICMI '03 International conference on Multimodal interfaces, Vancouver, British Columbia, Canada.

108. Chen S, Epps J, Ruiz N, Chen F (2011) Eye activity as a measure of human mental effort in HCI. IUI '11
Proceedings of the 15th international conference on intelligent user interfaces, Palo Alto, CA; United States.

109. Kolers PA, Duchnicky RL, Ferguson DC (1981) Eye movement measurement of readability of CRT displays. Human Factors 23(5): 517-527.

110. Tversky B (1974) Eye fixations in prediction of recognition and recall. Memory \& Cognition 2(2): 275278.

111. Guo K, Mahmoodi S, Robertson RG, Young MP (2006) Longer fixation duration while viewing face images. Exp Brain Res 171(1): 91-98.

112. Kowler E (1985) Smooth eye movements as indicators of selective attention. In: Posner MI, Marin OSM, (Eds.), Mechanisms of attention: Attention and performance XI , Erlbaum, Hillsdale, NJ, pp: 285-300.

113. Schneider WX, Deubel H (1995) Visual attention and saccadic eye movements: Evidence for obligatory and selective spatial coupling. Studies in Visual Information Processing, 6: 317-324.

114. Hoffman JE, Subramaniam B (1995) The role of visual attention in saccadic eye movements. Perception \& Psychophysics 57(6): 787-795.

115. Shepherd M, Findlay JM, Hockey RJ (1986) The relationship between eye movements and spatial attention. Quarterly Journal of Experimental Psychology 38(3): 475-491.

116. Barrios GV, Gutl C, Preis A, Andrews K, Pivec M, et al. (2004) AdELE: A Framework for Adaptive E-Learning through Eye Tracking. Proceedings of IKNOW, Graz, Austria.

117. Smit AC, Van Gisbergen KAM (1989) A Short-latency transition in saccade dynamics during square-wave tracking and its significance for the differentiation of visually-guided and predictive saccades. Experimental Brain Research 76(1): 64-74.

118. Xu-Wilson M, David SZ, Shadmehr R (2009) The intrinsic value of visual information affects saccade velocities. Experimental Brain Research 196(4): 475481. 